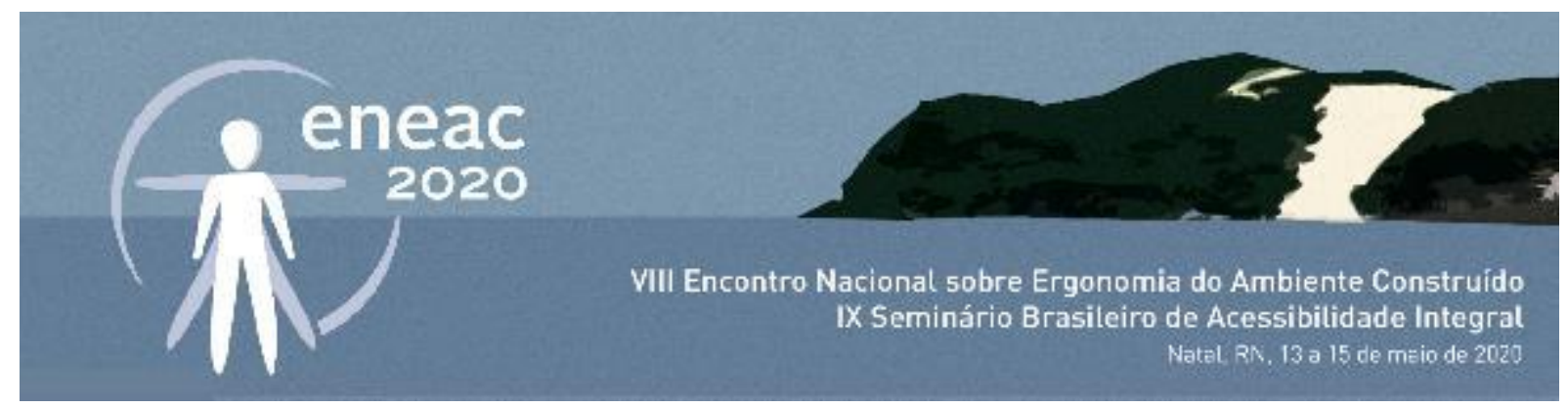

\title{
Incluir começa por ouvir: estudando a percepção ambiental de crianças com Síndrome de Down
}

\author{
Include starts by listening: studying the environmental perception of \\ children with Down Syndrome
}

VIRGINIA MAGLIANO QUEIROZ
Doutora, Faculdade Pitágoras, vimagliano@hotmail.com

SHEILA WALBE ORNSTEIN

Professora Titular, FAU USP, sheilawo@usp.br

GLEICE AZAMBUJA ELALI

Doutora, UFRN, gleiceae@gmail.com

\section{RESUMO}

A inclusão social de pessoas com deficiência (PD) é um tema em crescente evidência nos últimos 40 anos. No campo de Arquitetura e Urbanismo o assunto já resultou em inúmeras pesquisas voltadas para a acessibilidade do ambiente, quer às PDs quer à população como um todo; entre elas a escola tem sido um dos objetos de estudo mais trabalhados, em busca de maior bem-estar e qualidade de vida para seus usuários, em especial os estudantes e dentre eles as crianças - embora em geral elas sejam pouco consultadas diretamente, sobretudo aquelas com deficiência intelectual. A justificativa para essa situação está na dificuldade de entender sua opinião, e resultou no desenvolvimento de uma tese que propôs instrumentos para coleta de dados sobre a percepção do ambiente construído aplicáveis a crianças com Síndrome de Down (SD). Recortando a pesquisa realizada, este artigo tem o objetivo de apresentar alguns resultados obtidos na investigação, a fim de lançar luzes sobre a possibilidade de acatar a opinião de tais crianças na avaliação do ambiente construído. Conclui-se que as crianças com SD podem participar ativamente no processo avaliativo em $A U$, condição potencialmente extensível a outras pessoas com Síndrome de Down.

PALAVRAS-CHAVE: Crianças com deficiência intelectual; Síndrome de Down; inclusão; qualidade espacial.

\section{ABSTRACT}

The social inclusion of people with disabilities (PD) is a subject that has been growing in evidence for the last 40 years. In the field of Architecture and Urbanism the theme has already resulted in numerous researches aimed at the accessibility of the environment, to the PDs and to the general population; among than the school has been one of the most studied objects of study in search of greater well- 


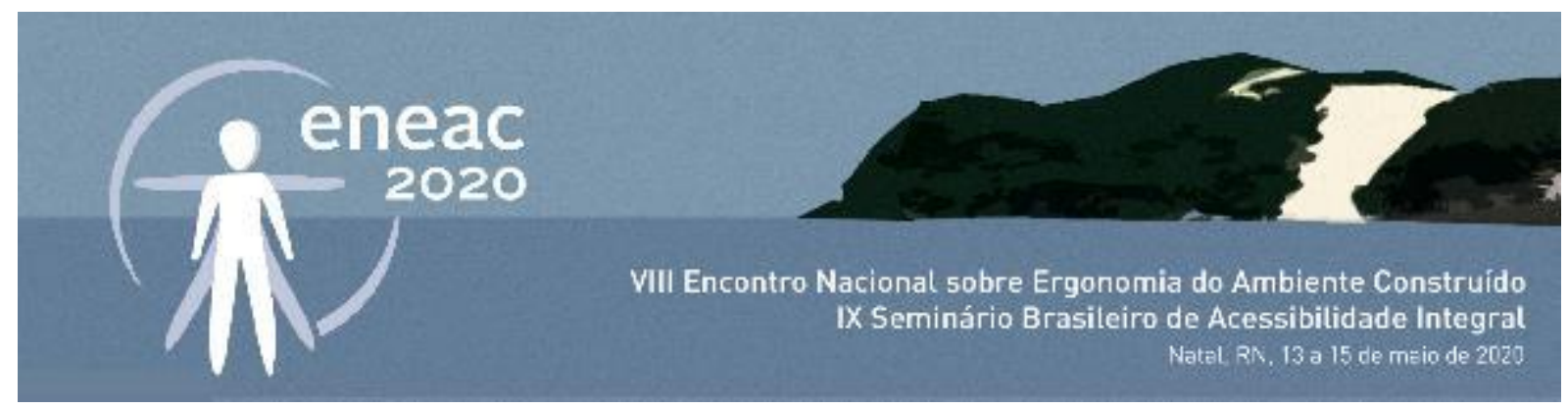

being and quality of life for users, especially the students and among than, the children - although in general they are little consulted directly, especially those with intellectual disabilities. The justification for this situation lies in the difficulty of understanding their opinion, and resulted in the development of a thesis that proposed instruments for collecting data on the perception of the built environment applicable to children with Down Syndrome (DS). The aim of this article is to present some results obtained in the research, in order show the possibility of accepting the opinion of such children in the evaluation of the built environment. It is concluded that children with DS can participate actively in the evaluation process in $A U$, a condition potentially extendible to other people with Down syndrome.

KEYWORDS: Children with intellectual disability, Down Syndrome, inclusion, spatial quality.

\section{INTRODUÇÃO}

Para as pessoas em geral, a escola é a primeira experiência de convívio e encontro social fora da família. Entretanto, até pouco tempo atrás as crianças com deficiência eram privadas dessa oportunidade. $O$ avanço das políticas mundiais de inclusão escolar abriu tal caminho, oferecendo para todos a possibilidade de convívio e aprendizado mútuo.

No Brasil, a inclusão escolar foi determinada pelo Decreto no 7.611 (BRASIL, 2011), que abrange todos os níveis de ensino e "todo e qualquer sujeito que se encontre excluído do processo escolar" (BRABO, 2013, p.15). Ela tem provocado um acentuado aumento no número de matrículas de estudantes com deficiência, transtornos globais do desenvolvimento e/ou altas habilidades (superdotação) no ensino regular. Segundo o Censo Escolar 2018 (MEC; INEP, 2019), cerca de 900 mil pessoas nestas condições estavam matriculadas em 2014, chegando a quase 1,2 milhão em 2018, um aumento de $33,2 \%$. Dentre os matriculados, $92,1 \%$ estavam incluídos em classes comuns.

Esses expressivos números, segundo a Organização para a Cooperação e Desenvolvimento Econômico $(\mathrm{OCDE})$, ainda podem estar subestimados, pois

\footnotetext{
crianças com distúrbios genéticos ou comprometimentos sensoriais geralmente são diagnosticadas no nascimento ou no início da infância, mas outras deficiências podem ser identificadas apenas anos mais tarde, e suas necessidades educacionais nem sempre são relatadas (OECD, 2012, p.4 - tradução livre das autoras).
}

Esse incremento na demanda exige que as escolas se preparem para atender tal população, garantindo que todos tenham acesso a "uma educação de qualidade, cada um a partir da realidade com que chega à escola, independentemente de raça, etnia, gênero, situação socioeconômica, deficiências etc." (SASSAKI, 2008, s/p). Além de questões psicopedagógicas ligadas ao acolhimento destes estudantes e à adaptação/criação de práticas socioeducativas as suas necessidades e limitações, tal movimento envolve, necessariamente, a adequação do espaço físico das instituições escolares. Todavia, nesse campo ainda existe um grande abismo entre a legislação existente e a prática/ fiscalização de seu cumprimento. Assim, nem sempre os ambientes internos e externos da escola estão adequados aos estudantes, mesmo aqueles que sem dificuldades em sua mobilidade. Com relação à qualidade espacial das edificações escolares, a práxis arquitetônica incorpora tanto elaborar projetos quanto avaliar o ambiente em uso, para o que a área de Avaliação Pós-Ocupação (APO) tem desenvolvido e aplicado todo um aparato teórico-metodológico especializado, em muitas situações tendo como base atividades inter-, multi ou transdisciplinares (ELALI, PELUSO, 2011). 


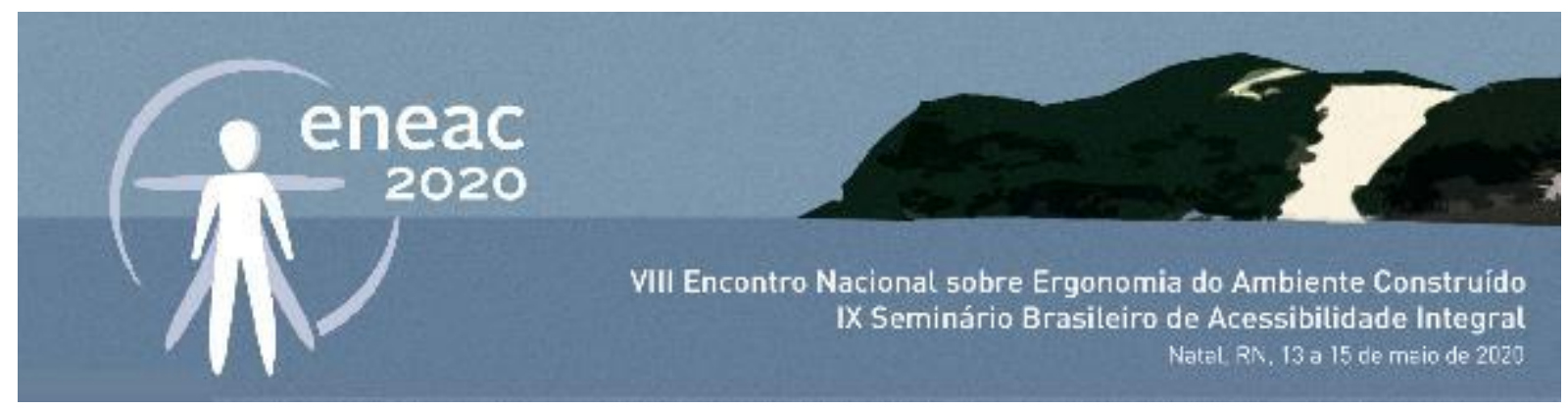

A APO teve origem na década de 1960, nos Estados Unidos da América (EUA) e na Inglaterra, como um campo da arquitetura responsável pela avaliação sistemática e rigorosa de edifícios após sua construção e ocupação por algum período (LI; FROESE; BRAGER, 2018). Contudo, essa nomenclatura só foi popularizada a partir de 1988, com a publicação do livro "Post-occupancy Evaluation"

(Avaliação Pós-Ocupação), de Preiser, Rabinowitz e White (1988), sendo ampliada e ajustada ao longo dos anos. Atualmente a APO é considerada, no Brasil, um conjunto de métodos e técnicas aplicado aos ambientes e às pessoas que os utilizam, a fim de aferir o desempenho físico do ambiente e a satisfação de seus usuários (ORNSTEIN; ONO; VILLA; FRANÇA, 2018). Ela possibilita diagnosticar aspectos positivos e possíveis necessidades de intervenções com vistas à melhoria do ambiente em estudo no decorrer do uso, o que ocorre a partir da investigação de alguns fatores pré-determinados, para tanto considerando a opinião dos especialistas (quer sejam avaliadores, projetistas ou instituições) e dos usuários (em suas diversas vinculações com o local).

No entanto, grande parcela da população ainda é excluída desse tipo de consulta aos usuários, sobretudo as pessoas com deficiência e, dentre elas, especialmente as pessoas com dificuldades intelectuais - e ainda mais se tratando de crianças. Tal situação é academicamente justificada em função da dificuldade de comunicação com elas; aliás, em alguns momentos a própria literatura questiona se crianças teriam condições de emitir opiniões confiáveis (FERNANDES, 2016), dúvida que se intensifica em se tratando de pessoas com deficiência intelectual.

Entendendo-se que um primeiro passo na direção de incluir as pessoas é tentar ouvir sua opinião (como indica o título desse artigo), foi realizada uma pesquisa de doutorado de caráter exploratório e qualitativo (QUEIROZ, 2019) que desenvolveu instrumentos metodológicos a serem aplicados por arquitetos a crianças pequenas (4 a 7 anos incompletos) com Síndrome de Down.

Como um recorte do trabalho realizado, e para demonstrar o potencial de participação de crianças com Síndrome de Down (SD) na avaliação do ambiente construído - sinalizando, portanto, a possibilidade de sua participação no processo de avaliação do ambiente construído -, este artigo focaliza as principais respostas obtidas na pesquisa. Seu objetivo é mostrar a viabilidade e a potencialidade desse tipo de investigação, e não realizar uma avaliação de desempenho do ambiente (para o que seria preciso outro tipo de estratégia, ao menos no que se refere ao tratamento dos dados). Desenvolvendo essa ideia, o artigo está dividido em três itens: inicialmente ele discorre brevemente sobre o método utilizado; em seguida comenta a participação das crianças (resultados); terminando por tecer considerações finais sobre o assunto.

\section{METODOLOGIA}

A investigação voltou-se para a percepção espacial das crianças com SD, especificamente para sua satisfação em relação à qualidade espacial, utilizando como plano de fundo para o estudo uma sala de atendimento terapêutico de uma instituição especializada. Para tanto foram desenvolvidos três instrumentos metodológicos construídos de modo lúdico e em linguagem infantil, tendo como base: a revisão bibliográfica (ABATE, 2011; GOULART; SPERB, 2008; SANOFF, 1991; ARFOUILLOUX, 1976; ABERASTURY, 1982); as indicações de profissionais da área (QUEIROZ; ORNSTEIN; ELALI, 2017); as sugestões dos pais. Os três instrumentos foram: Prancha de Qualificação Espacial, Cartões Ilustrados e "Faz de Conta" em Modelo Tridimensional Físico (QUEIROZ, 2019), como segue: 


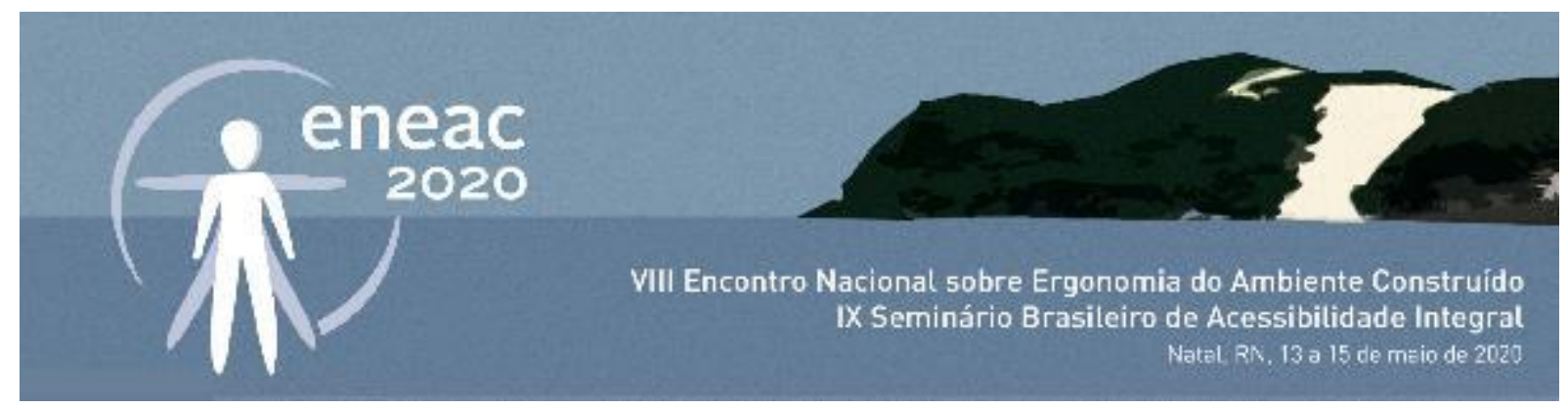

- A Prancha ..... (Figura 1) solicitou que a criança comparasse dois ambientes que the eram familiares, discriminando-os a partir da atribuição de corações ao favorito.

- Nos Cartões llustrados (Figura 2) pedia-se que o participante selecionasse imagens relacionadas à sala onde estava (o conjunto de imagens era formado por fotografias de móveis e objetos, inclusive brinquedos presentes no local e em outros ambientes da instituição), a fim de demonstrar se reconhecia o local.

- O Modelo ..... (Figura 3) consistia em maquete do local onde a atividade acontecia, sobre a qual a pesquisadora conduzia uma conversa, utilizando como escala humana um personagem de interesse da criança. A investigação também recorreu à fotografia, à filmagem das sessões e à elaboração de diário de campo da pesquisadora.

Figura 1 - Prancha de Qualificação Espacial - Instrumento I.

\section{O QUE VOCÊ GOSTA MAIS?}
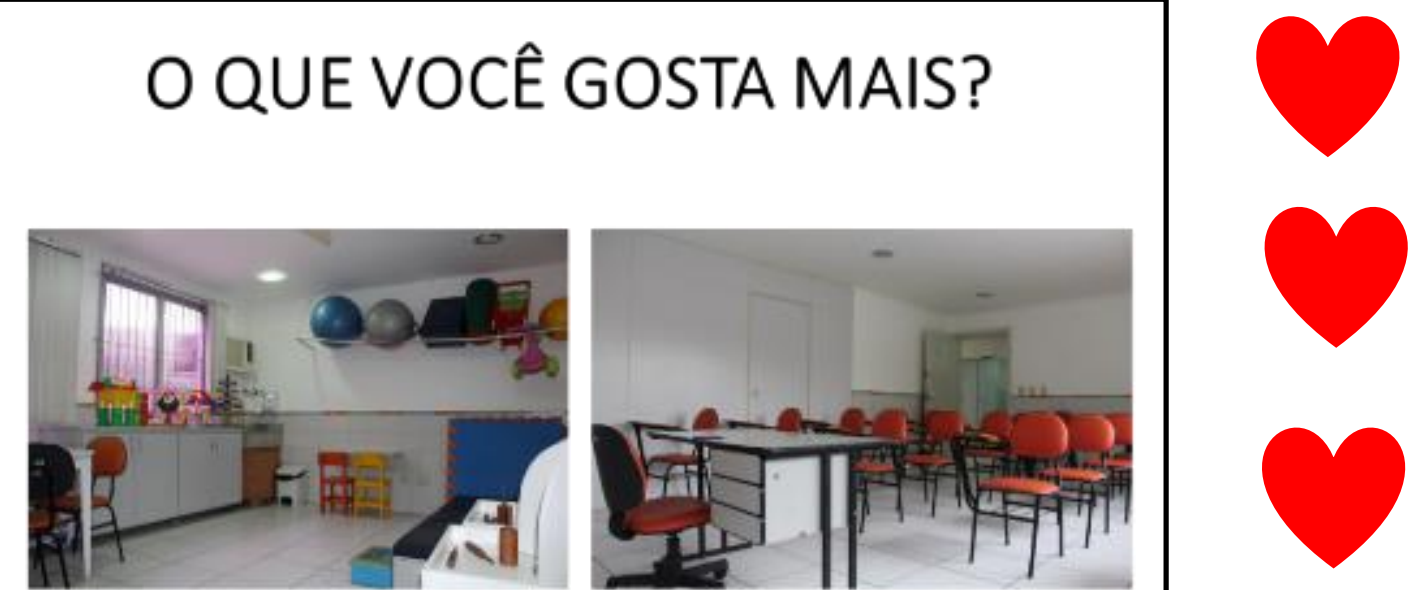

Fonte: Queiroz, 2019.

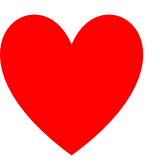

Figura 2 - Alguns dos Cartões llustrados - Instrumento II.
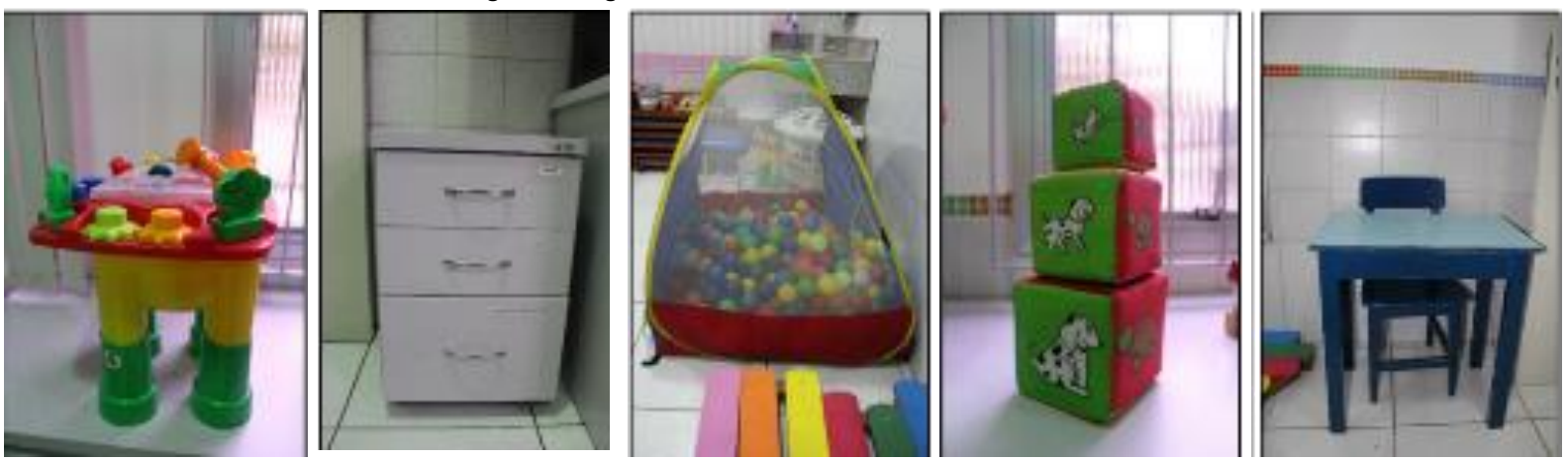

Fonte: Queiroz, 2019. 

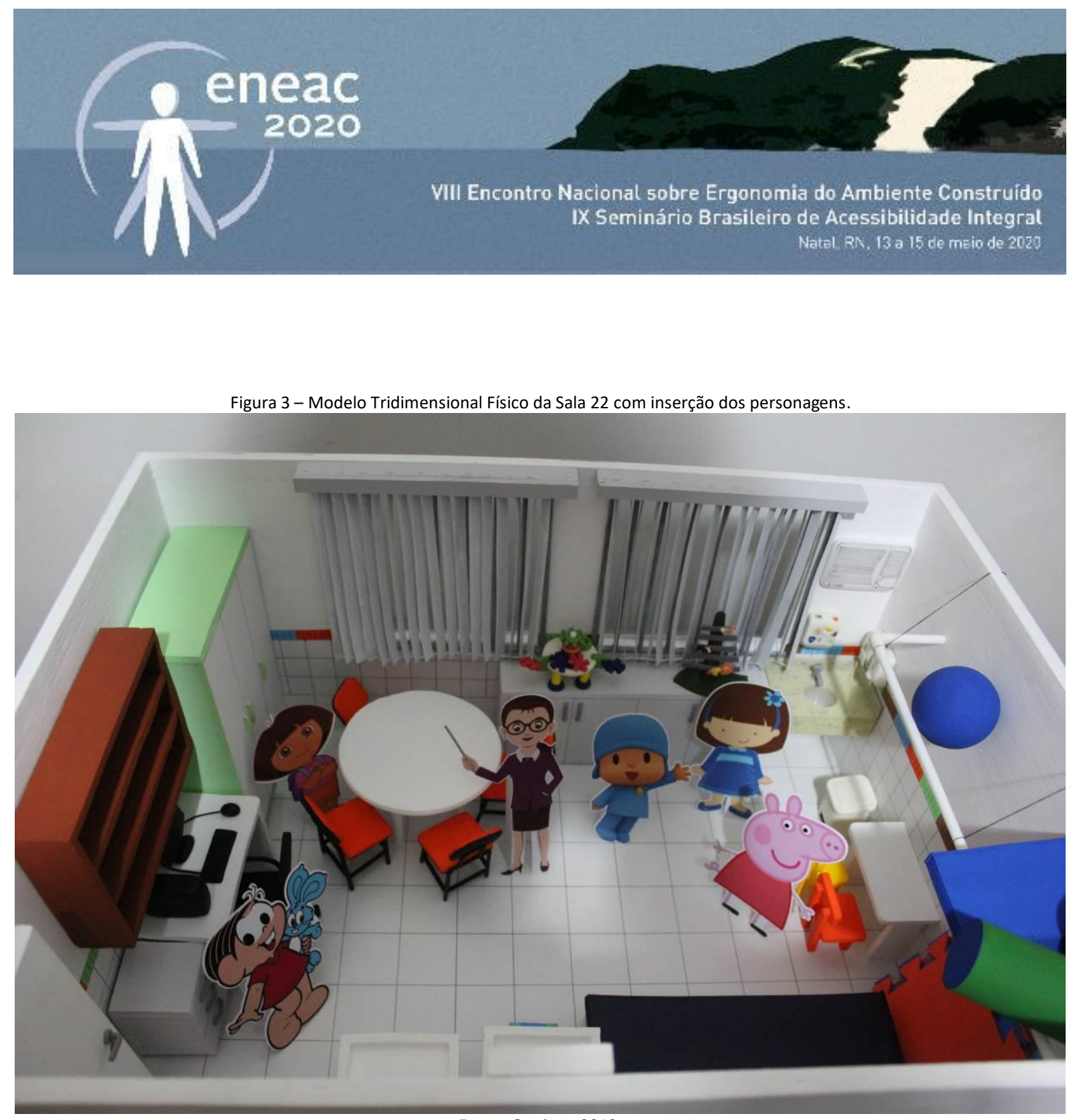

Fonte: Queiroz, 2019.

Participaram onze crianças com Síndrome de Down, oito meninos e três meninas, cuja idade variou entre 4 e 7 anos. A maioria das crianças participantes utilizava linguagem verbal, embora se comunicasse majoritariamente por gestos e apontando objetos, além de usar palavras de difícil compreensão por alguém de pouco convívio. Optou-se por focalizar crianças em idade pré-escolar por entender que a escolarização seria um facilitador do processo de pesquisa, o que poderia restringir os resultados obtidos, que seriam aplicáveis apenas a pessoas escolarizadas, condição que (infelizmente) ainda não corresponde à realidade desse grupo, ao menos no contexto brasileiro.

A pesquisa aconteceu entre outubro e novembro de 2018, em uma instituição especializada no atendimento de crianças com deficiência intelectual localizada em Vitória, Espírito Santo. O tempo médio de aplicação dos instrumentos foi de 50 minutos, acontecendo em um ou dois encontros, dependendo da situação.

A investigação foi aprovada pelo Comitê de Ética em Pesquisa (CEP) do Hospital Universitário da Universidade de São Paulo (HU/USP), selecionado pela Comissão Nacional de Ética em Pesquisa (CONEP), no processo no. 51657415.0.0000.0076 com aprovação em 11/12/2015 Entre os principais cuidados, além da anuência da instituição, a investigação recorreu ao Termo de Consentimento Livre 


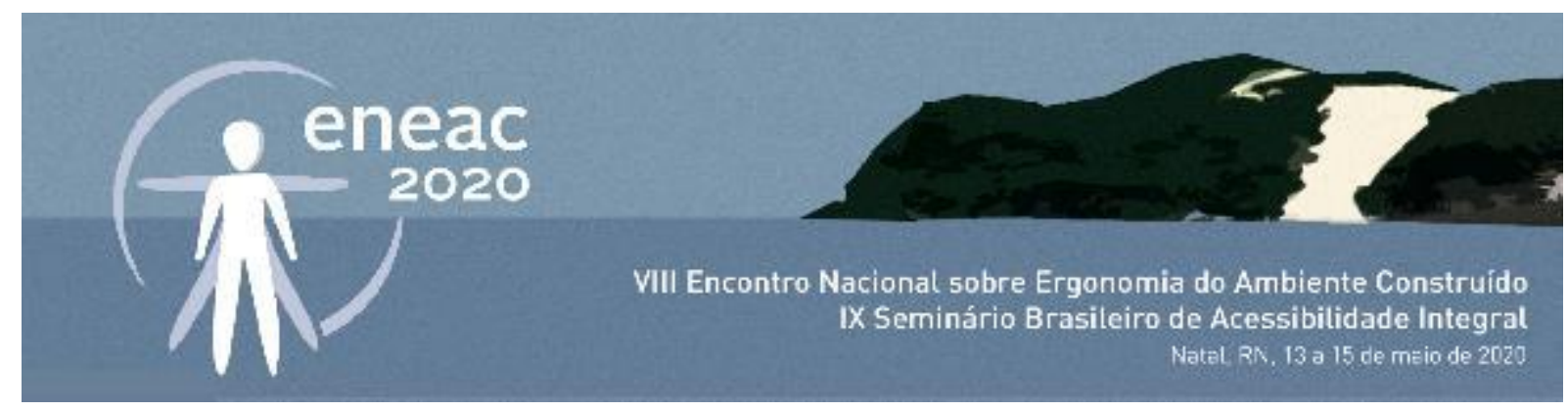

e Esclarecido (TCLE), específico para os responsáveis, e ao Termo de Assentimento Livre e Esclarecido (TALE), apresentado às crianças.

\section{PRINCIPAIS RESULTADOS: A PARTICIPAÇÃO INFANTIL}

Em geral as crianças participantes acataram bem a atividade e foram sociáveis, permanecendo sozinhas com a pesquisadora durante quase todo o tempo das sessões, mesmo num primeiro contato. Apenas em momentos pontuais foi necessário recorrer ao auxílio de um profissional ou do pai/mãe do/a participante a fim de obter sua cooperação.

No geral, as atividades despertaram o interesse dos participantes, embora também tenham acontecido tentativas de fuga, caracterizadas por agitação/dispersão ao serem contrariados ou quando sentiam não saber responder algo. Poucas crianças permaneceram todo o tempo focadas nas atividades e na pesquisadora, mesmo assim, com um pouco de paciência e respeito ao tempo e às necessidades de cada uma, a aplicação dos instrumentos aconteceu à contento.

Na primeira atividade, as crianças foram convidadas a explorar um ambiente não familiar. Quase todas interagiram com esse espaço, apesar de algumas terem apresentado alguma resistência para adentrá-lo. Apenas uma criança se recusou a interagir com o ambiente, permanecendo ao lado da pesquisadora no interior da sala, com a cabeça baixa, e os olhos voltados para o chão, sem nenhuma intenção de explorar ou entender o local.

Ao apresentar a Prancha de Qualificação Espacial (painel com duas fotografias de salas), o protocolo de pesquisa indicava que a pesquisadora fizesse algumas associações entre fotografia e realidade, a fim de verificar se os participantes conseguiam percebê-las. A grande maioria deles demonstrou reconhecer o local e suas características, quase todos apontando sequencialmente para os elementos reais e os da fotografia. Duas crianças sinalizaram essa associação somente no segundo encontro, o que não interfere na pesquisa, visto que indica sua compreensão da tarefa, mesmo que tenha sido necessário maior tempo para que esse processamento acontecesse (embora também possam ter feito tal distinção desde o início, mas sem indica-lo claramente). Apenas uma criança não sinalizou ter associado a imagem ao ambiente real, de modo que a pesquisadora não soube se ela compreendeu as imagens ou não.

$\mathrm{Na}$ aplicação dos Cartões llustrados todas as crianças demonstraram interesse pela atividade, mesmo aquelas que estavam um pouco dispersas e necessitaram que a pesquisadora insistisse mais em motivá-los. Em termos de desempenho, nove crianças identificaram elementos da sala presentes nas cartas apresentadas ( 9 dentre 11 crianças): cinco delas apontaram tudo o que era da sala, mesmo confundindo um gaveteiro; e duas identificaram todos os elementos que foram mostrados a elas, embora se mostrado cansadas e, por isso, não tenham concluído a tarefa. Ou seja, a maioria das crianças (sete delas) apontou objetos que conhecia, e quando não os reconhecia, demonstrou por meio de comportamentos específicos (como fixar o olhar na carta ou na pesquisadora, dizer "NÃO", apontar para a porta de entrada, ou mesmo não apresentar reação - um modo de dizer que a pergunta "não se aplicava").

Por fim, no "Faz de conta" em Modelo Tridimensional Físico, todas as crianças se interessaram bastante pela maquete, mesmo que após insistência ou a inserção de personagens em papel (na escala da maquete). A grande maioria delas rapidamente fez associações entre as miniaturas e os 


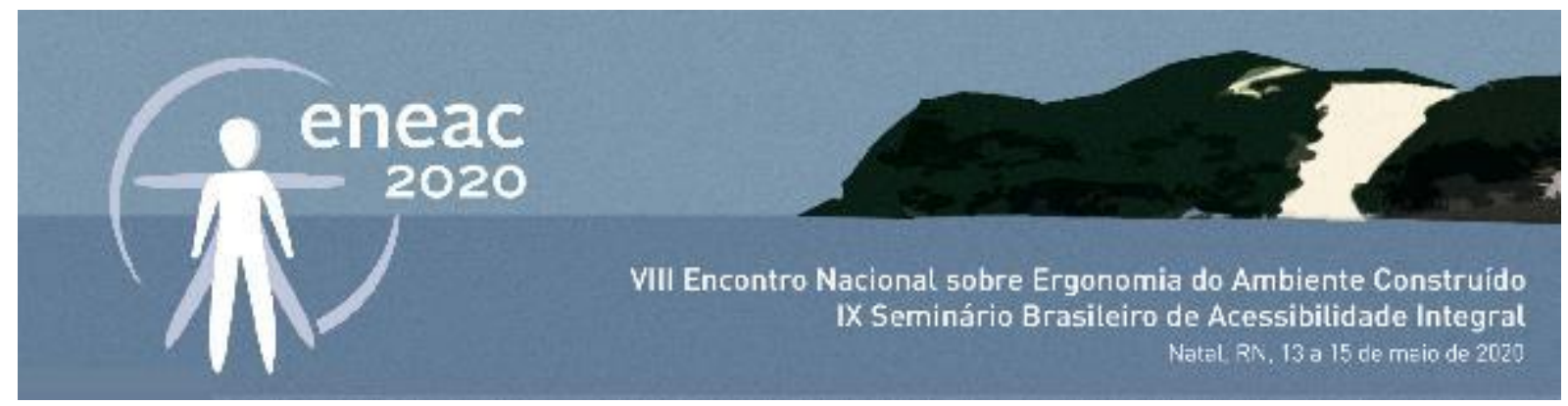

elementos reais da sala. Apenas uma delas não o fez, e outra se interessou mais em brincar com os elementos em miniatura (no "faz de conta", um tubo verde virou megafone e o gaveteiro um telefone), mas mesmo assim identificou um dos elementos, antes de se dispersar totalmente e preferir brincar.

Algumas crianças participantes conseguiram identificar quase todas as miniaturas, incluindo pia, cortina, gaveteiro, triângulo para apoio de pernas, um tubo verde estofado e tapetes de Etil Vinil Acetato (E.V.A.). Outras identificaram poucos elementos, o que não é um problema, visto que mesmo um resultado pouco expressivo sinaliza a capacidade de associação entre miniatura e realidade.

Demonstrando identificar o ambiente e identificar-se com a maquete, a maioria das crianças tentou abrir armários, gaveteiros e lixeira em miniatura, e quis puxar a porta pela maçaneta. Algumas simularam batidas na porta. Outras tentaram 'entrar' na maquete, seja colocando o pé no vão da porta, por cima da parede ou até mesmo tentando sentar-se dentro dela. Tais comportamentos reforçam que os participantes associaram a maquete à realidade, chamam atenção para a seriedade com que as crianças encaram o "faz de conta" e, ainda, sinalizam a intenção delas participarem mais efetivamente dele. Quando tentavam entrar na maquete, ou utilizavam as miniaturas como bonecos, a pesquisadora imediatamente inseria os personagens, explicando que apenas eles poderiam entrar naquele local.

Na maioria dos casos o uso de personagens para auxiliar na tarefa se mostrou adequada. Em geral, os personagens cumpriram seu papel, levando as crianças a comentarem situações do dia-a-dia dos atendimentos (locais onde ficam, o local ocupado pela terapeuta ocupacional, comportamentos cotidianos como abrir e fechar porta, ou caminhar pela sala com os bonecos). Apesar dessa facilitação, os personagens não foram muito eficazes na tarefa de qualificação do ambiente, pois apenas três crianças sinalizaram, de alguma forma, gostar (ou não) de elementos presentes na maquete.

\section{CONSIDERAÇÕES FINAIS}

Em síntese, ao analisar as reações e as respostas aos instrumentos aplicados, a maioria das crianças demonstrou perceber bem o ambiente, o relacionou à miniatura e às fotografias, identificando os objetos e móveis semelhantes (tamanho real $\mathrm{x}$ miniatura ou realidade $\mathrm{X}$ imagem). Por outro lado, verificou-se maior dificuldade na qualificação do ambiente e de seus elementos. Ao se depararem com duas fotografias de ambientes diversos, lado a lado, aparentemente, todas as crianças conseguiram escolher o que gostavam mais. Porém, o mesmo não se repetiu em relação ao modelo físico tridimensional que, embora tenha sido muito bem aceito pelos participantes, não trouxe o retorno esperado, pois poucas crianças responderam ao questionamento qualitativo (quer verbalmente quer por meio de gestos).

Portanto, mesmo se tratando de um estudo exploratório, os resultados da pesquisa demonstraram ser possível mobilizar crianças com SD para atividades ligadas à percepção e avaliação do ambiente construído, o que evidencia seu potencial para participar desse tipo de investigação e abre um interessante caminho de pesquisa em Arquitetura e Urbanismo.

Embora tenha sido difícil obter respostas de algumas das crianças, e nem todas tenham sido mobilizadas/atingidas da mesma maneira, a maioria participou adequadamente, informando seus 


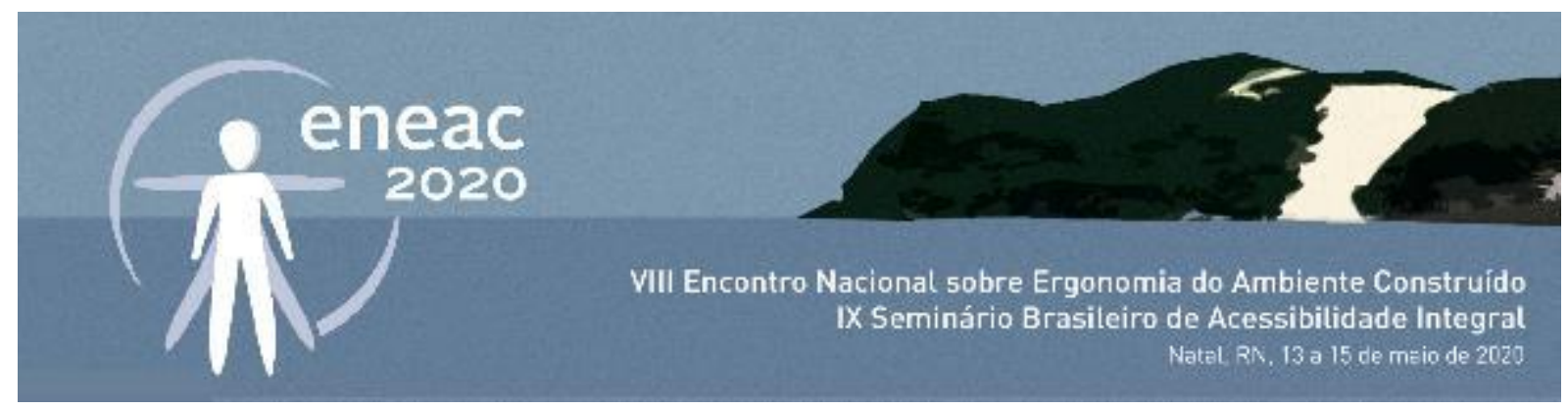

gostos e opinando sobre os ambientes e seus elementos. Mesmo nos casos com maior dificuldade de verbalização, esta condição não foi empecilho, pois as crianças desenvolvem formas de comunicação não verbal capazes de expressar seus interesses e intenções.

Apesar da investigação apresentada nesse artigo ter envolvido apenas crianças pequenas e de ter acontecido em escala reduzida (poucos participantes), sua realização demonstra uma possibilidade concreta de se considerar a opinião de pessoas com SD em pesquisas que visem o reconhecimento da qualidade espacial das edificações e sua melhoria. Nesse sentido, simplesmente ter intenção de inclui-las não é suficiente, é preciso tentar (e aprender a) entrar em contato com elas, respeitar seu tempo e seu tipo de linguagem. Valorizar seu ponto de vista como interlocutoras ativas poderá ser mais um passo para sua inclusão social, além de contribuir para a elaboração de projetos de edifícios e para o planejamento de espaços urbanos mais adequados a todas as pessoas. Afinal, reiteramos, incluir começa por ouvir.

\section{AGRADECIMENTOS}

As autoras agradecem:

— às instituições, profissionais, pais e crianças participantes da pesquisa, pela confiança;

- à Faculdade de Arquitetura e Urbanismo da Universidade de São Paulo (FAU-USP) e ao Curso de Arquitetura e Urbanismo da Universidade do Rio Grande Norte (CAU-UFRN) pelo apoio propiciado;

- ao Conselho Nacional de Desenvolvimento Científico e Tecnológico (CNPq), pelo financiamento parcial ao trabalho por meio de bolsas de produtividade em pesquisa da segunda e da terceira autoras - financiamento código 001.

\section{REFERÊNCIAS}

ABATE, Tania Pietzschke. Instrumentos de Avaliação Pós-Ocupação (APO) adaptados a pré-escolares com deficiência física, auditiva e visual. 2011. Tese (Doutorado em Arquitetura e Urbanismo), Faculdade de Arquitetura e Urbanismo, Universidade de São Paulo, São Paulo, 2011. Disponível em: http://www.teses.usp.br/teses/disponiveis/16/16132/tde27012012-094114/pt-br.php. Acesso em: 30 abr. 2019.

ABERASTURY, A. Psicanálise da Criança: teoria e técnica. Porto Alegre: Artmed, 1982.

ARFOUILLOUX, J. C. A Entrevista com a Criança: a abordagem da criança através do diálogo, do brinquedo e do desenho. Rio de Janeiro: Zahar Editores, 1976.

BRABO, G. M. B. Formação docente inicial e o ensino ao aluno com deficiência em classe comum na perspectiva da educação inclusiva. Tese (Doutorado em Educação). UFRGS, Porto Alegre, 2013. Disponível em: file:///C:/Users/Virginia/Desktop/BRABO,\%202013.pdf. Acesso em: 22 mai. 2019.

BRASIL. Decreto no 7.611, de 17 de novembro de 2011. Dispõe sobre a educação especial, o atendimento educacional especializado e dá outras providências. Diário Oficial da União, Brasília, DF, 2011.

ELALI, Gleice Azambuja; PELUSO, Marília. Interdisciplinaridade. In: S. CAVALCANTE; G. A. ELALI. (Org.). Temas básicos em Psicologia Ambiental. 01ed.Petropolis: Vozes, 2011, p. 227-238.

GOULART, C. M. T.; SPERB, T. M. Histórias de crianças: as narrativas de crianças asmáticas no brincar. In: S. H. V. CRUZ (Org.). A criança fala: a escuta de crianças em pesquisas. São Paulo: Cortez, 2008. p. 351-354. 


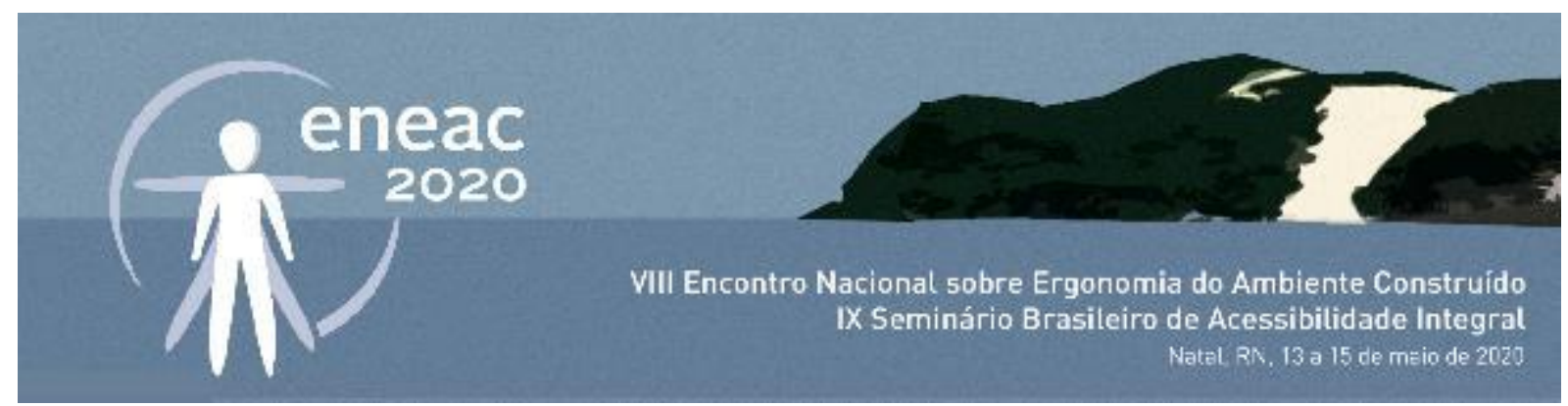

LI, P.; FROESE, T. M.; BRAGER, G. Post-occupancy evaluation: State-of-the-art analysis and state-of-the-practice review. Building and Environment. 133, 2018. p. 187-202. Disponível em: https://doi.org/10.1016/j.buildenv.2018.02.024. Acesso em 03 mai. 2019.

MINISTÉRIO DA EDUCAÇÃO (MEC); INSTITUTO NACIONAL DE ESTUDOS E PESQUISAS EDUCACIONAIS ANÍSIO TEIXEIRA (INEP). Censo Escolar 2018: notas estatísticas. Brasília, 2019. Disponível em: http://download.inep.gov.br/educacao_basica/censo_escolar/notas_estatisticas/2018/notas_estatisticas_censo_escola r_2018.pdf. Acesso em: 22 mai 2019.

ORGANIZATION FOR ECONOMIC CO-OPERATION AND DEVELOPMENT (OECD). Special Educational Needs (SEN). 2012. Disponível em: http://www.oecd.org/els/family/50325299.pdf. Acesso em: 05 jun. 2019.

ORNSTEIN, S. W.; ONO, R.; VILLA, S. B.; FRANÇA, A. J. G. L. Avaliação pós-ocupação (APO) aplicada à realimentação do processo de projeto. In: R. ONO; S. W. ORNSTEIN; S. B. VILLA; A. J. G. L. FRANÇA (Orgs.). Avaliação Pós-Ocupação: na arquitetura, no urbanismo e no design: da teoria à prática. São Paulo: Oficina de Textos, 2018. p. 19-47.

PRADO, R. L. C. A participação de crianças em pesquisas brasileiras das ciências sociais e humanas. Tese (Doutorado em Psicologia), Instituto de Psicologia da Universidade de São Paulo. São Paulo, 2014.

PREISER, W.F.E.; WHITE, E.; RABINOWITZ, H. Post-occupancy Evaluation. New York: Van Nostrand Reinhold, 1988.

QUEIROZ, V. M.; ORNSTEIN, S. W.; ELALI, G. A. Qualidade espacial para crianças com deficiência intelectual: a contribuição de especialistas. In: SIMPÓSIO BRASILEIRO DE QUALIDADE DO PROJETO NO AMBIENTE CONSTRUÍDO. Anais... João Pessoa / Porto Alegre: ANTAC, 2017.

QUEIROZ, Virginia Magliano. Qualidade espacial para pessoas com deficiência intelectual: investigando modos de obter a opinião de crianças pequenas com Síndrome de Down. 2019. 278 p. Tese (Doutorado em Arquitetura e Urbanismo), Faculdade de Arquitetura e Urbanismo, Universidade de São Paulo, São Paulo, 2019.

SANOFF, H. Visual research methods in design. New York: Van Nostrand Reinhold, 1991.

SASSAKI, R. K. Artigo 24 - Educação. In: A. P. C. RESENDE; F. M. P. VITAL (Coord.). A Convenção sobre os Direitos das Pessoas com Deficiência Comentada. Brasília: SEDH/CORDE, 2008, p. 83. 